\title{
A Review of Discourse Power Research Based on the Content Analysis Method-Takes CSSCI Journal Articles from 2008 to 2019 as Samples
}

Chu Yan*, Chen Xiangling

English Department, Foreign Language School, North China Electric Power University, Baoding, Hebei, China

DOI: $10.36348 /$ sijll.2020.v03i04.006 $\quad$ | Received: 02.04.2020 | Accepted: 09.04.2020 | Published: 27.04 .2020

*Corresponding author: Chu Yan

\section{Abstract}

At present, with people's deepening understanding of the relevant functions and nature of discourse, discourse power is also attached importance by the country and all walks of life, and discourse right has increasingly become a topic of great concern to scholars. This paper adopts content analysis method to study journal articles with discourse power as the key words published in CSSCI journals from 2008 to 2019. From the research hot topics, research purposes, research methods, subject distribution, fund projects and other aspects of quantitative and qualitative statistical analysis, combing the research status of the discourse power in the past eleven years, and put forward a rich discourse theory foundation for the remaining shortcomings. We will make some suggestions on building a new era of discourse power structure system and strengthening the construction of an innovative talent training system for discourse rights. We hope to provide reference for the application practice and development of dialogue and speech rights research.

Keywords: Discourse power; the content analysis method; quantitative and qualitative statistical analysis.

Copyright @ 2020: This is an open-access article distributed under the terms of the Creative Commons Attribution license which permits unrestricted use, distribution, and reproduction in any medium for non-commercial use (NonCommercial, or CC-BY-NC) provided the original author and source are credited.

\section{INTRODUCTION}

In recent years, the situation at home and abroad is changing with each passing day. Discourse power, as a right related to the speech of all sectors of society and the right to defend one's own discourse, has witnessed an increasing upsurge of discourse power research and the emergence of relevant research results. According to their own research fields and their respective academic backgrounds, domestic scholars conducted multidimensional researches on the scientific connotation of discourse power, the necessity, practical challenges and realization paths of discourse power promotion in their respective fields. Scholars from all walks of life have published tens of thousands of papers in various journals (With the theme of "discourse power" alone, 17,052 articles can be retrieved on CNKI). In the process of discourse power research becoming more and more multidimensional and wideranging, Whether the quality of discourse power research is improving? Whether progress has been made on some important theoretical and practical issues? This is an important issue related to whether the study of discourse power can guide practice. At present, a few scholars have systematically studied the discourse power, and found some problems. Such as Liu Rongwu[1]in his Overview of Discourse Rights Research mentioned that researches on enhancing international discourse power have no praiseworthy advantages; Lack of empirical research ; The reconstruction of discourse power becomes a new subject. Zhang Guobiao[2]pointed out in his Overview of the Research on the Discourse Right of Ideological and Political Education in Colleges and Universities that discourse theory in colleges and universities is not innovative enough, Lack of applied research; Results are scattered and lack of systematic research. In Research review on the realization of online discourse power and the monitoring mechanism of public opinion, Zhai Xinmei[3]points out that the research on the power of online discourse is few in quantity, single in perspective, and the breadth and depth of the research content need to be improved.; In literature review of women's discourse power in recent years, , Liu Bingyi[4]proposed combined with actual cases, mining and exercise theory; In a review on the ideological discourse power of the Chinese dream, Zhou Yinzhen[5] thought there is controversy about the research standards for the ideology of the Chinese dream; Recent studies lack of theoretical research and creativity. Based on the above studies, we can see that the main problems in the current research on discourse power are as follows: : First, The lack of theoretical research of discourse power; Second, The lack of empirical research : Third, The lack of a unified 
standard in the study of discourse power; Fourth, The study of discourse power lacks certain creativity, and the research topics and viewpoints are similar; Fifth, Dispersed results; Sixth, Insufficient systematic research. At the same time, the author found that the overview of discourse power lacks sufficient and powerful support of quantitative research, which makes the findings of various discourse power research problems unconvincing. Therefore, it is necessary to systematically analyze and sort out the existing results, and draw up its research status, development trends and general problems, and provides some reference for future discourse power research. In view of this, this paper sorts out the research on discourse power and analyzes the hot spots, research purposes, subject distribution and development trend of discourse power research in the past 11 years, so as to provide references for the research on discourse power in China and promote the further improvement of the research level in this field.

As a kind of literature research method, content analysis method systematically and objectively describes the contents of the literature, clearly reveals the basic facts and development trends of the research objects, and explores the deep content contained in the research to predict its development trend[6].This study attempts to use the content analysis method to describe and evaluate the number of papers, research purposes, themes, theoretical foundations, and author composition of the discourse power published in the CSSCI journals in China for nearly 11 years. To understand the intrinsic relationship between the research focus and research content of this research field, and to predict and master the latest developments in academic research in this field. The implementation of content analysis method includes: first, putting forward research questions, determining the source of the overall research objectives; second, selecting research samples; then coding, counting and processing the sample; finally systematically interpreting and analyzing the statistical data to obtain research results[7]. According to this step, this paper will conduct statistics and combing on the basis of quantitative data, and conduct qualitative analysis on the content of the literature.

\section{RESEARCH DESIGN \\ Research problems}

This study is intended to answer the following questions: 1) What is the basic status of discourse power research from 2008 to 2019? 2) What are the hot topics of discourse power research? 3 ) Can the theoretical study of discourse power meet the needs of practice? 4) What is the national and local attitude towards discourse power research? 5) What are the new developments in discourse power research?

\section{RESEARCH METHODS Data Sources}

At present, there are many types of academic journals, and the level of academic papers is uneven. Therefore, scientifically refining data sources and literature selection criteria to obtain reliable data is the key part of high-quality research. The Chinese Social Science Citation Index (CSSCI) database was developed by Nanjing University. It covers a wide range of research fields. It uses a combination of quantification and qualitative methods to select normative and strong academic journals as the source journals, it's the most important and the most common source database in social science research, it's also the important choice of the social science researchers of literature search. Therefore, the data source of this paper is CSSCI to ensure the quality of study samples.

\section{Data collection and processing}

Firstly, with "discourse power" as the key word of the paper, the journal source was set as CSSCI, and 965 relevant papers were retrieved on November 13, 2019. After the data source is determined, query and download the title, abstract, keyword, publication date, journal name, author and other information of 965 related papers, and save this information to Note Express. Then, according to the search results, quantitative visualization analysis was carried out to obtain the trend graph of published articles, keyword distribution, subject distribution and other information. Finally, carry out the corresponding statistics and analysis.

\section{Code}

The 965 articles were coded according to seven aspects in table 1 . The coding work was jointly completed by two authors, and they all reached an agreement in seven aspects.

Table-1: Variable and Classification

\begin{tabular}{|l|l|}
\hline Variable & Classification \\
\hline Year & 2008-2019 \\
\hline Published papers of DP & -------- \\
\hline Keywords distribution & -------- \\
\hline Research purposes & 1.Theoretical research \\
\hline & 2.Applied research \\
\hline Research method & 1.Quantitative research \\
\hline & 2.Qualitative research \\
\hline Disciplines distribution & 1.Politics \\
\hline
\end{tabular}




\section{RESULTS AND DISCUSSION}

Statistics on the publication of discourse power

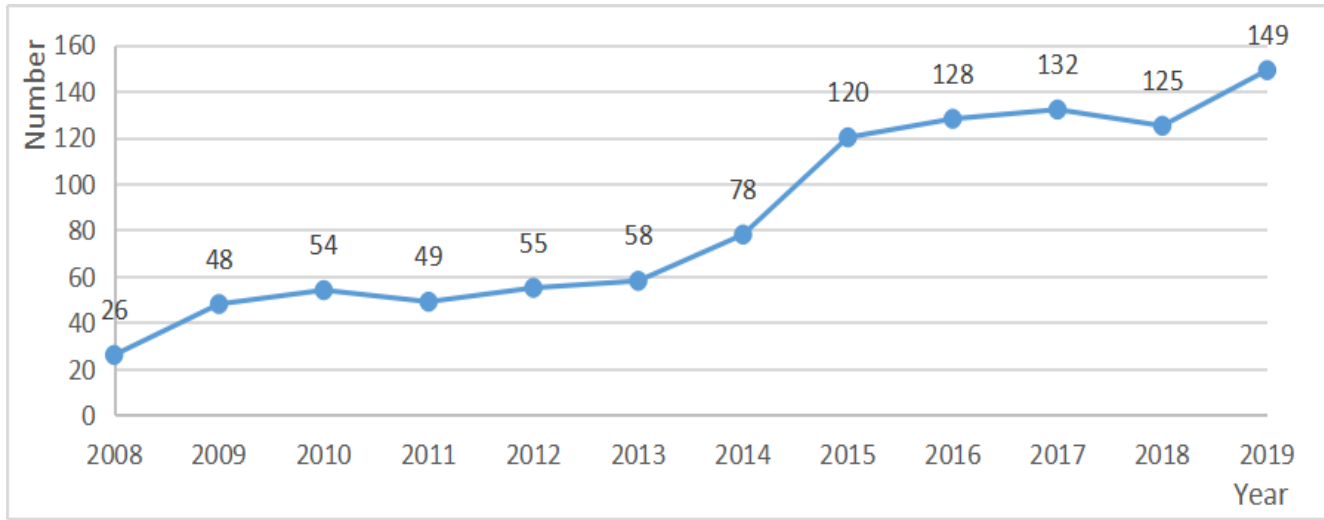

Fig-1:2008 — 2019 Posting trend of discourse power research

As shown in Figure 1, although the amount of papers on discourse power in the past eleven years has fluctuated slightly in a short period of time, it showed an overall upward trend and reached a peak of 149 in 2019. In the past 11 years, 965 papers related to discourse power have been published on CSSCI, with an average of 87 papers per year. It can be seen that the research on discourse power has gradually become a hot topic and focus of academic research at this stage.

In November 2012, at the 18th National Congress of the Communist Party of China, president $\mathrm{Xi}$ Jinping repeatedly emphasized the need to work hard to improve the international discourse power, "speaking Chinese stories well and spreading Chinese voices well." This initiative has undoubtedly raised the concern of the study of discourse power in all walks of life. In July 2014, the National Language Proficiency Development Center was established at Beijing Foreign Studies University. This initiative of the National Language Committee undoubtedly promoted the research progress of discourse power. It is a major event in the research and development of the right to speak in China. It is also the result of the unremitting efforts of scholars from all walks of life in China. According to this, we will use this period as a turning point. The study of discourse rights is broadly divided into two stages, 2008-2013 and 2014-2019. The statistics of the number of posts in these two phases are:

Table-2: Statistics of publishing papers at two stages

\begin{tabular}{|l|c|c|c|}
\hline & the first stage & the second stage & total \\
\hline The number of published papers & 290 & 675 & 965 \\
\hline
\end{tabular}

According to the statistical results in table 2, the number of papers published in the second stage increased significantly, indicating that the research on discourse power has attracted more and more attention of scholars from all walks of life and made remarkable achievements. Reflecting on its reasons, this is closely related to the expansion of the discourse power research team, especially the national attention to the discourse power. So what is the main content and research focus of discourse power research? In order to explore this problem, we made statistics on the key words of discourse power research.

\section{Keywords co-occurrence}

Key words play a guiding role in academic research. The frequent application of certain keywords in a certain subject area indirectly presents the current research hot topics and interests in this field. Therefore, based on the research literature with the title of "discourse power", the author sorts out some highfrequency keywords of the sample, in order to analyze the research hot topics in the field of current discourse rights. The keyword co-occurrence results are shown in Figure 2. 


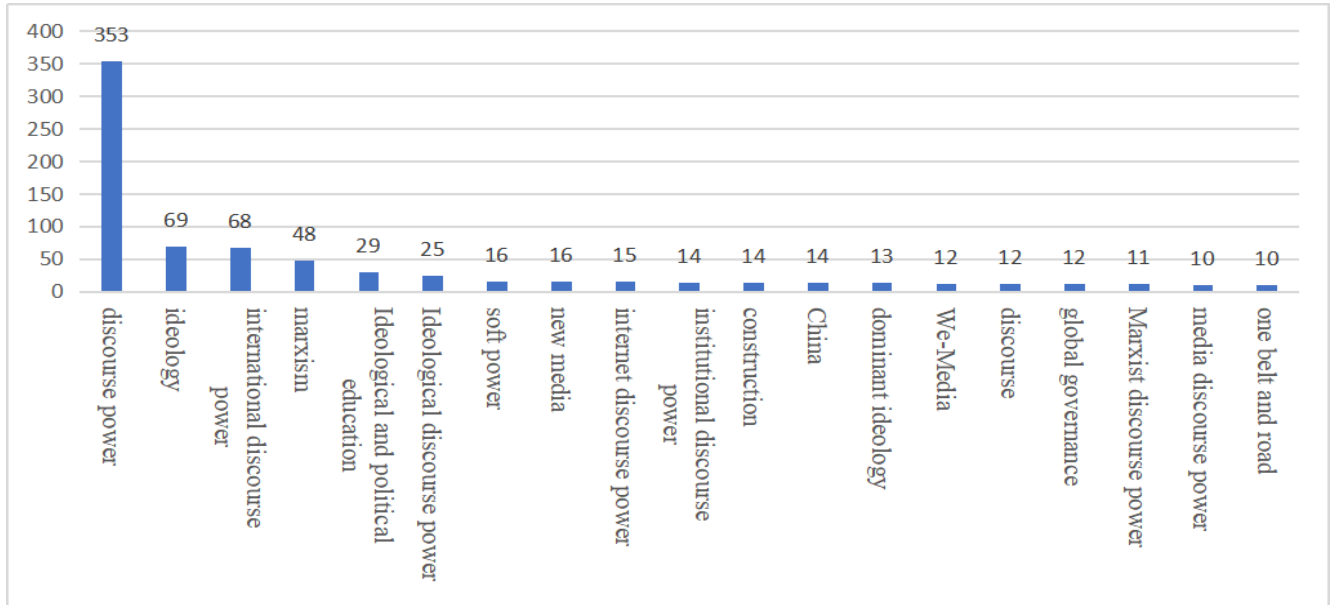

Fig-2: Keywords distribution of discourse power research

As shown in figure 2, "discourse power" is the most frequently used keyword in the literature, appearing 351 times, which is closely related to the literary theoretical background of discourse power research. Secondly, "ideology", "international discourse power" and "marxism" appeared 69 times, 68 times and 48 times respectively, which coincides with the current policy orientation of the country to attach importance to the construction of international discourse power; It is worth noting that "Ideological and Political Education", "Ideological Discourse power", "Soft Power", and "New Media" appear 29 times, 25 times, 16 times, and
16 times respectively, indicating that discourse power research scholars actively refer to other theoretical methods in their research, thus, it forms the characteristics of the intersection and integration of discourse power and other subject areas. On the one hand, it broadens the scope of discourse power research, and on the other hand, it is undoubtedly a major innovation in discourse power application research. What about the theoretical research on discourse power? Therefore, the author makes a statistical analysis on the theoretical and applied research of discourse power.

\section{RESEARCH PURPOSES AND METHODS}

Table-3: Statistical table of discourse power research purpose

\begin{tabular}{|c|c|c|c|}
\hline & $\mathbf{2 0 0 8 - 2 0 1 3}$ & $\mathbf{2 0 1 4 - 2 0 1 9}$ & Total \\
\hline Theoretical research & $11(3.79 \%)$ & $65(9.62 \%)$ & $76(7.89 \%)$ \\
\hline Applied research & $279(96.2 \%)$ & $610(90.37 \%)$ & $889(92.12 \%)$ \\
\hline
\end{tabular}

Table-4: Statistical table of discourse power research methods

\begin{tabular}{|c|c|c|c|}
\hline & $\mathbf{2 0 0 8 - 2 0 1 3}$ & $\mathbf{2 0 1 4 - 2 0 1 9}$ & Total \\
\hline Quantitative research & $12(4.14 \%)$ & $45(6.66 \%)$ & $57(5.91 \%)$ \\
\hline Qualitative research & $278(95.9 \%)$ & $630(93.33 \%)$ & $908(94.1 \%)$ \\
\hline
\end{tabular}

As can be seen from table 3, in general, theoretical research accounts for $7.89 \%$ and applied research for $92.12 \%$ of the discourse power research purposes. The proportion of applied research papers is significantly higher than that of theoretical research papers, which indicates that the theoretical research of discourse power is far behind the need of discourse power practice. As can be seen from table 4, among the methods used to study the discourse power, qualitative research methods are favored by the majority of scholars, accounting for $94.1 \%$. On the contrary, quantitative research is relatively scarce, accounting for only $5.91 \%$. In the past 11 years, there has been no significant change in discourse power research, which emphasizes application over theory, quality over quantification.
The applied research of discourse power is far more than the theoretical research. On the one hand, it is because the research of discourse power cannot be separated from specific subjects, which makes the discourse power widely used. On the other hand, with the constant change and development of the international and domestic situation, the research on discourse power at the national level has been paid more and more attention, which has attracted the attention of scholars from all walks of life and kept the research on discourse power hot. Different scholars combine their own research fields and interests to interpret and apply the discourse power from different perspectives, so that the discourse power research increasingly presents a trend of multidisciplinary integration. Therefore, the author makes a statistical 
analysis on the subject distribution of discourse power in the following part.

Studies on discourse power are mainly qualitative analysis and lack of quantitative research, which, to some extent, makes discourse power research inevitably have strong subjective color. Meanwhile, different scholars have different opinions on the definition of discourse power, and no unified conclusion has been formed. Lack of objective data to support analysis, research is not convincing enough. The author suggests that qualitative research method should be combined with quantitative research method. Starting from quantitative analysis and combining with qualitative analysis, objective and thorough discussion on discourse power should be carried out.

\section{Disciplines distribution}

Table-5: The disciplines distribution of discourse power research

\begin{tabular}{|c|c|c|}
\hline discipline & number & percentage \\
\hline Politics & 247 & $26.94 \%$ \\
\hline News and Communication & 160 & $17.45 \%$ \\
\hline Marxism & 112 & $12.21 \%$ \\
\hline Education & 100 & $10.91 \%$ \\
\hline Literature & 28 & $3.05 \%$ \\
\hline Law & 26 & $2.84 \%$ \\
\hline Society & 26 & $2.84 \%$ \\
\hline Philosophy & 25 & $2.73 \%$ \\
\hline History & 19 & $2.07 \%$ \\
\hline Language & 18 & $1.96 \%$ \\
\hline Public management & 18 & $1.96 \%$ \\
\hline Theoretical economics & 16 & $1.74 \%$ \\
\hline National economy & 15 & $1.64 \%$ \\
\hline Culture & 14 & $1.53 \%$ \\
\hline Physical education & 12 & $1.31 \%$ \\
\hline
\end{tabular}

It can be seen from Table 5 that the subject's distribution of discourse power research is mainly concentrated in Politics, News and Communication, Marxism, and Education. The total number of papers in the distribution of these four disciplines is 619 , accounting for $67.51 \%$, reflecting on the reasons, this is inseparable from a series of national policies. In 2009, Liu Yunshan,a member of the Political Bureau of the CPC Central Committee, wrote in the magazine "Seeking Truth" that the essence of the competition for news is to compete for the right to speak. And highlighting the need to use strong public opinion to win the right to speak and take the initiative。Building a top-ranking media with a wide range of audience. extensive information multilingualism and high influence ; On January 4th, 2010, Li Changchun put forward higher requirements on the ability of public opinion guidance and international communication at the National Propaganda Ministerial Meeting, and instructed that new steps should be taken to seize the right of speaking and win the initiative; In the "Decision of the Central Committee of the Communist Party of China on Deepening the Reform of the Cultural System and Promoting the Great Development and Prosperity of Socialist Culture" adopted by the Sixth Plenary Session of the Seventeenth Central Committee in October 2011, the "Innovative External Spring Method" was adopted to enhance the international voice. , properly respond to external concerns..." ; In the 18th and 19th National People's Congresses, the call on improving the international discourse power has been repeatedly mentioned and emphasized by national leaders。There are many other fields which are closely related to discourse power have received attention such as literature, law, society, and philosophy (28 articles; 26 articles; 26 articles, 25 articles). With the emphasis on the construction of national discourse power, different disciplines have begun to study the dialectical power from their perspectives. History, language, public management, theoretical economics, national economy, culture, sports and other disciplines have continuously introduced discourse power study. It further shows the tendency that the study of discourse power is widely integrated with other disciplines.

\section{The specialization of the subject}

According to the production, improvement, enrichment and development of discourse power, I divides the specific subjects of discourse power research into three aspects: construction, deconstruction and reconstruction. 


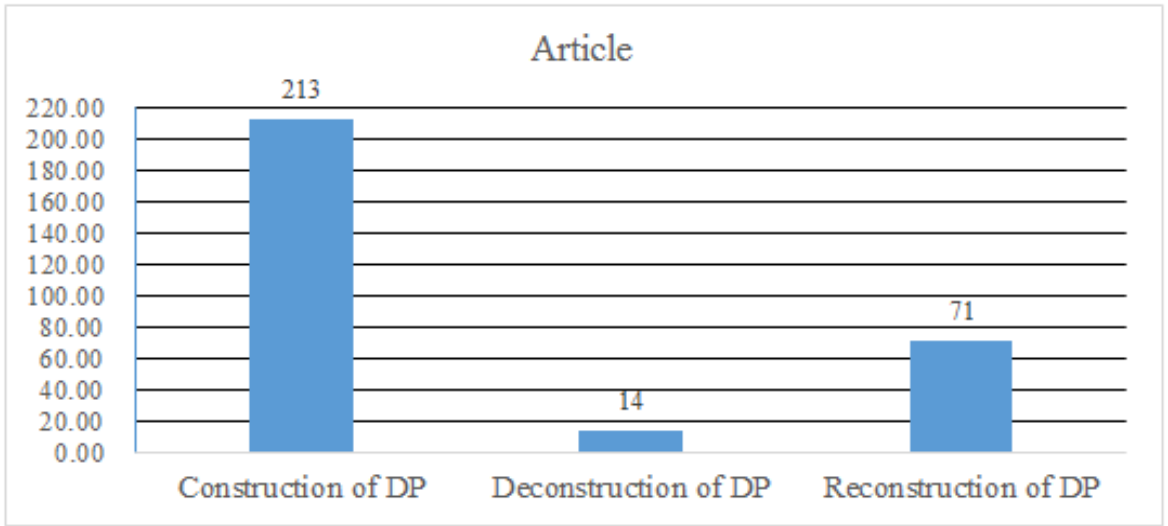

Fig-3: The specialization of the subject

From the perspective of research topic specialization (Fig. 3), the discourse rights research scholars pay more attention to the construction of discourse power, a total of 213 articles, accounting for $22.07 \%$. Different scholars explored how to construct discourse rights from different fields, but most of them start from a big perspective and propose similar approaches to realize discourse power, basically, it can be summarized as improving discourse ability, building top-ranking media and and enhancing the setting of international issues. Secondly, there are 71 papers concerning the reconstruction of the discourse power, accounting for $7.35 \%$, with the network technology is increasingly convenient today, the public has more ways to express their discourse rights, and the allocation of social discourse rights has also changed, discourse reconstruction has increasingly become a new topic for scholars to explore.

\section{CONCLUSION AND SUGGESTION}

\section{Achievements of discourse power researches}

Achievements in discourse power research are mainly reflected in academic achievements and contents. In terms of academic achievements, by November 13th, 2019, 17052 related papers can be retrieved. In terms of academic content, although the concept of discourse power has not been unified, it has argued from the aspects of subject, purpose and essence, which is conducive to the determination of discourse power. At the same time, it is able to keep pace with the Times and seize the hot spots and the main position of discourse power, deeply analyses discourse power issues from their respective professional fields, We have a new exploration and clear understanding of the relevant theories 、 the realization path platform construction and other problems, all these achievements are worthy of our affirmation.

\section{Deficiencies of discourse power researches}

\section{Discourse ontology research lacks unified standards} and has a lot of controversy

Under the call of academic freedom, scholars from all walks of life interpret the discourse power from different perspectives based on their own academic background and interests. However, due to the lack of unified standards, various interpretations are difficult to judge temporarily, which is not conducive to the development of the discourse right itself. Such as, Chen Shuguang, Liu Ying[8]believe that discourse power is essentially a kind of cultural soft power and an external manifestation of cultural soft power; Ding Huimin[9] believes that "discourse power" is the right to speak, that is, the right to control public opinion by means of language, words, images, symbols, etc; Feng Guangyi [10] thinks that "discourse power" is the right of people to obtain speech opportunities through the exchange of ideas and speech ; Li Xiaojun [11] regards "discourse power"as the right of participating in commenting on political affairs, which reflects citizens' right of expression and participation; Ge Yandong [12] proposes that what the discourse power of ideology possesses is the "right" which reflects class interests; Chen Zhengliang [13] believes that the international discourse power is not only the right of a country to "speak" on the world's stage, but also the effectiveness and power of "speak"; Zhang Xinping and zhuang Hongtao [14] regard international discourse power as the power in the field of international relations, which is the right of sovereign states to express opinions, transmit values, participate in the formulation of international rules, and describe, explain, evaluate and regulate international events by means of diplomacy, media, cooperation and communication ; Mei Jinghui [15] stated that ideological discourse power is composed of two dimensions: cultural leadership and political leadership; Hou Yong [16] indicated that the discourse power of ideological and political education includes the right to control work discourse, the right to lead subject discourse and the right to dominate theoretical discourse. He believed that its influence, leading power and attraction were formed in political practice; Zhang Zhizhou [17] proposed that a country's international discourse power is the power obtained through discourse, which is essentially a kind of "power" just like military and economic power.

Therefore, it can be seen that various interpretations of discourse power are not accurate enough to form an unified definition, and the definition 
of discourse power connotation is more descriptive than normative, which is not conducive to in-depth research. Therefore, the theory of discourse power urgently needs to be explored systematically and theoretically.

\section{The breadth and depth of DP research should be further expanded.}

Although different scholars discussed how to improve the discourse power in China from different fields, they mostly started from the big perspective of discourse power construction and lacked empirical research, which eventually led to the similar methods and paths of improving the discourse power in China from different articles of different ideas, although different scholars have discussed the way of improving discourse power from different fields in China, they mostly from the macro perspective to explore the approaches of constructing discourse power, and lack of empirical research, which eventually leads to the similar methods and paths of improving the discourse power in China, they can be roughly summarized as creating top-ranking media, building the discourse platform, actively participating in the international agenda setting, and optimizing the discourse structure. Besides, when it comes to discourse power proposition, most scholars discuss it from the perspective of enhancing discourse power. However, with the fastchanging domestic and international situations, the research should not be limited to the construction of discourse power. We also should pay attention to rebuild the theory, structure and path of discourse power which are suitable to the times. Moreover, the topics and viewpoints of discourse power research are mostly similar and lack of innovation. Sometimes, the theoretical research lags behind the practical needs, and most scholars only explain the practical problems existing in the research of discourse power, instead of finding and solving the practical problems.

\section{The results are scattered and lack of systematic research}

As for the research on discourse power, the academic research perspective is mostly limited to the scholars' personal expertise, and the research fields are mostly concentrated in the fields of politics, news, Marxism and education. These studies are hot topics and key issues at present, which indeed require in-depth research. But at the same time, we cannot ignore other aspects, such as theoretical and empirical studies. This is also a very important level. In the long run, if only pay attention to the hot topics of the times and neglecting other aspects of discourse power, it will increasingly show the characteristics of "fragmentation", "patch-type", "seeking and dismantling", and passive abnormal development, which is not conducive to the systematic research of discourse power and limit the in-depth discussion of current hot topics.

\section{Lack of quantitative research}

Most of the research on discourse power only remains at the level of qualitative subjective analysis. Different scholars analyze and interpret discourse power from various perspectives, but such research lacks of quantitative research supported by objective data which inevitably make the research of discourse power with strong subjective color, and lack of certain persuasiveness , practicality and operability. This is not only the weakness but also the of the breakthrough point of discourse power research.

\section{Future prospects of this research}

Enrich the theoretical basis of discourse and build the structure system of discourse power in the new era. In a word, the construction of discourse system is the foundation of discourse power, and linguistic theory is more suitable for this task. The Langue/Parole [18] proposed by Saussure from the perspective of sociolinguistics and the Competence/Performance [19] proposed by Chomsky from the perspective of psychology are of great significance to the research of discourse theory. The well-known scholar Wen Qiufang [20] once divided the national language ability into two levels in Connotation of National Discourse Competence-New Understanding of National Language Proficiency: Intrinsic national language ability (LanguelCompetence) and national language externalization ability (ParolelPerformance), and point out that the former is the foundation and premise of the latter. Wen Qiufang puts forward some Suggestions and measures to solve the problems in the construction of "national discourse capacity" in China; establish an authoritative organization to manage national discourse strategic affairs; Construct a way of discourse expression which is easy to remember, understand, and accept for all countries. Tell Chinese stories well and spread Chinese voices well. What is more important point is to respond to the public's demands of discourse power.

\section{Construct the training system of innovative talents with discourse power}

The development of the right to speak in China cannot be separated from the talents that change with time and events, and also the talents with innovative thinking. Therefore, it's of great importance to cultivate the innovative talents with innovative thinking. It is believed that the guidance and cultivation of national discourse ability should be emphasized in the field of basic education, and establish courses in colleges and universities which are related to discourse power research. Both at the national and local levels, it is necessary to build a powerful talent training program and a high-end think tank for the development of national discourse power, hopes to make new breakthroughs in innovative discourse thinking and improving propagative notions and strategies. 


\section{REFERENCES}

1. Liu, Rongwu, W.Y. (2018). Literature review of discourse power research, Journal of News Research, 9(2018) 143-144.

2. Zhang, G. (2018). Discourse power in ideological and political education in colleges and universities, Journal of Hubei Correspondence University, 31, 74-76.

3. Zhai, X., Pan, Y.(2016). Research review on the realization of online discourse power and the monitoring mechanism of public opinion, Journal of Wuhu Institute of Technology, 18: 79-81.

4. Liu, B. (2014). Literature review of women's discourse power in recent years, Chuanbo $\mathrm{Yu}$ Banquan, 111-112.

5. Zhou, Y. (2016). A review on the ideological discourse power of the Chinese dream, Journal of Chongqing University of Post and Telecommunications (Social Science Edition), 28(2016) 19-26.

6. Zi-kun, M. A., \& Li-juan, P. E. N. G. (2013). Analysis on Research Status and Development Trends of Domestic Institutional Repository Based on Content Analysis. Library Tribune, (5), 7.

7. Junping, Q., \& Fei, Z. (2004). A Study of Content Analysis Methods [J]. The Journal of The Library Science In China, 2.

8. Chen, S. (2016). Liu Ying, on the evolution law of discourse power, Seeker, 22-26.

9. Ding, H., Hu, X. (2016). Discourse power analysis of network big V Internet "micro space", China Higher Education, 45-47.

10. Feng, G.(2008). Discourse power, Journal of Fujian Normal University (Philosophy and Social Science Edition), 54-59.
11. Li, X. (2010). Analysis of "power of discourse" in "network anti-corruption", Theoretical Exploration, 122-125.

12. Ge, Yandong.(2015). Grasp the ideological discourse power preliminary exploration, Leadin Journal of Ideological Theoretical Education, 7377.

13. Chen, Z., Zhou, Jie, Li, B. (2014). An analysis on the nature of international discourse power -- and on what China should do to enhance international discourse power, Zhejiang Social Sciences, 78-83

14. Zhang, X., Zhuang, H.(2017). China's international discourse: journey, challenges and strategies for improvement, Nankai Journal (Philosophy, Literature and Social Science Edition), 1-10.

15. Mei, J.(2017). Cultural confidence and contemporary development of discourse power of marxist ideology, Studies on Marxism, 103-112.

16. Hou, Y. (2016). Discourse of power and discourse power: construction and transformation of discourse power in ideological and political education, Theory and Reform, 133-137.

17. Zhang, Z. (2017). Several fundamental theoretical problems in the construction of international discourse power, in: Study Times, 2.

18. Saussure, F. De. (1959). A course in general linguistics $[\mathrm{M}]$. New York: The Philosophical Library.

19. Chomsky, N. (1965). Aspects of the theory of syntax [M]. Cambridge, Mass: MIT Press.

20. Wen, Q. (2017). The connotation of national discourse competence -- a new understanding of national language competence, Journal of Xinjiang Normal University (Edition of Philosophy and Social Science), 38; 66-72. 